\title{
Urban Water Supply Management and Water Supply Safety Countermeasures
}

\author{
Yao Fengchun \\ Water Supply Bureau of Shandong Yellow River Bureau, Jinan, China
}

\section{Email address:}

122703986@qq.com

\section{To cite this article:}

Yao Fengchun. Urban Water Supply Management and Water Supply Safety Countermeasures. Science Innovation. Vol. 9, No. 4, 2021, pp. 179-181. doi: 10.11648/j.si.20210904.23

Received: May 20, 2021; Accepted: June 25, 2021; Published: July 9, 2021

\begin{abstract}
With the development of social economy, the scale of towns is expanding, the quality of life is improved, and the water supply safety is more and more concerned. Urban water supply as the key component of urban infrastructure construction, in order to ensure the safety of water quality, to avoid different nature of water quality pollution, to different management objects and system analysis, understand the factors affecting water quality, using scientific management methods, construction of perfect urban water supply security and quality assurance management system. And establish a certain period, regularly control urban water supply pipes and auxiliary facilities, find and control and deal with problems in time. The transformation of urban pipe network should promote and apply new pipe materials, which can avoid the secondary pollution of pipe materials. To sum up, the current water supply system management and urban water supply system is serious, backward management technology and supervision technology, aging water supply pipe network and insufficient capital investment all affect the management of water supply system and water supply safety, relevant departments should pay attention to and control, and do a good job in problem solving and control
\end{abstract}

Keywords: Smart Water System, Urban Water Supply, Application, Research

\section{城镇供水管理及供水安全对策}

\section{姚逢春}

山东黄河河务局供水局, 济南市, 中国

\section{邮箱}

122703986@qq.com

摘要：随着我国社会经济的发展, 城镇规模不断扩大, 人们生活品质的提高, 供水安全问题越来越受到重视。城市居 民正常生活需要足够以及高质的水资源作为保障, 这样大众才能正常的进行生产和生活, 发挥自身在社会中作用, 促 进社会各个行业更好的发展, 维持社会经济活动的良好运行状态。目前, 城市化发展进程加快, 城市人数数量上涨, 扩大对水资源的需求。为了实现安全和高质供水服务, 城市供水期间, 要重视水系统损坏和污染水质等安全问题的管 控, 避免对水安全生产带来更为严重的影响。本文分析城镇供水管理以及供水安全对策相关内容, 力求通过现状的分 析, 探索解决水污染以及水系统损坏等安全问题举措, 确保供水工作顺利开展, 为大众生产以及生活及时提供高质水 资源服务。

关键词：城镇, 供水管理, 供水安全, 对策 


\section{1. 引言}

城市供水作为城市基础设施建设关键构成, 对保障 城市供水起着至关重要的作用。随着我国社会经济的发 展, 城镇规模不断扩大, 人们生活品质的提高, 供水安 全问题越来越受到重视 [1]。为了确保水质的安全, 以免 出现不同性质的水质污染问题, 要针对不同管理对象以 及系统进行分析, 了解影响水质的各个因素, 后利用科 学的管理方法进行管理, 建设完善的城市供水安全保障 以及质量保障管理体系。并建立一定周期, 定期对城市 供水管道和辅助设施等进行管控, 发现问题及时管控和 处理。城市管网的改造, 要推广和应用新型管材, 可以 避免管材出现二次污染 [2]。总而言之, 目前城市供水系 统管理以及安全形势严峻, 管理技术与监管技术落后、 供水管网出现老化问题、资金投入不足等均影响供水系 统管理和供水安全, 相关部门要加以重视和管控, 做好 问题的解决与管控工作。

\section{2. 城镇供水管理及供水安全现状分析}

\section{1. 水资源较为短缺, 整体水环境严峻}

经过多年的努力, 使得我国城市水环境污染的趋势得 到基本的控制, 一些城市与地区地下水环境质量得到有效 改善, 但是整体水环境的形式依旧较为严峻, 污染物的排 放量较大[3]。此外, 城市用水量的不断增加, 也导致城市 排水量不断增加, 此时, 若是城市污水处理建设工作未及 时跟进, 也将导致出现污水问题, 一些无法及时处理的污 水被排放, 对城市的建设带来不良影响[4]。

\section{2. 供水管理技术以及监管手段较为落后}

近些年, 水环境污染较为严重, 且呈现不断加剧的现 状。如, 部门城市中供水厂水质量监测能力相对薄弱, 水 质检测的手段较为传统和单一, 导致水质安全缺失有效的 技术作为保障。此外, 目前智能化技术以及在线技术、信 息技术高速发展, 电厂未利用先进监管以及管理技术进行 自动化监管, 也影响水环境管控效率和效果 [5]。

\section{3. 水质量问题以及供水安全问题突出}

水质量问题就是水在自然属性方面出现的问题, 其也 是城市供水安全问题的核心。如果水质量出现安全问题, 供水水质被使用, 将导致人体出现长期以及短期的健康问 题, 对其身体健康带来较大危害 [6]。导致供水出现安全以 及质量主要问题因素包括，原水水质量问题、管网输配期 间出现的二次污染问题、水厂的设备以及预处理工艺较为 落后、输配水管网较为陈旧等, 均导致水质量出现不同程 度的问题[7]。

\section{4. 供水管网出现老化问题, 资金投入不足}

部分城市的供水管网已经铺设和被应用长达六七十 年之久, 超过五十年的寿命应用周期, 管材的质量就大打 折扣, 无法良好的运行。尽管一些区域重视此类问题的管
控, 但是因为资金问题, 仅是单一的进行维护和加固处理, 未进行彻底的更换, 也导致出现用水安全问题。如一些地 区的土质质量时湿陷性黄土地, 遇到雨水容易出现不同程 度的塌陷问题, 这样产生的压力过大, 将导致出现钢筋混 凝土自流沟以及水管出现断裂, 这样将对用水的安全性带 来严重威胁和影响。

\section{3. 城镇供水管理及供水安全工作举措}

\section{1. 优化产业布局, 重视水资源的保护}

目前, 我国水资源严重短缺, 使得我国部门城市的供 水较为困难。针对这一现状, 要想解决城市供水困难问题, 必须从源头进行管控, 以免水源和水质受到污染 [8]。此外, 政府以及各个部门也要给予足够的重视, 重点对水源地实 施保护, 依据《环境保护法律制度》等相关法律法规进行 保护, 组织和制定水源的保护计划, 以此强化水资源管控 效果。

重视水质监督检查。相关单位应严格执行国家相关规 定, 保证各级水质监督检查工作的有序开展, 保证对城市 各供水企业督查的效果。对违规的企业要严格处罚力度, 以此提高城市供水企业的供水安全[9]。

对水源环境的质量因素进行分析, 针对影响水源环境 的因素, 采取和应用科学、有效的举措进行管控和保护[10], 如, 通过提高水资源环境绿化的覆盖率以及防治水源地的 环境污染, 和对当下已经出现污染源制定针对性治理举措 进行治理, 均可以强化对水资源的保护, 使得水源环境处 于一个受控的状态 [11]。

\section{2. 实施开源节流举措, 建设预警与管理机制}

现阶段, 我国城市中供水系统均是采取单一的水源进 行供水, 该供水方式最大的缺点为保障性功能过差, 使得 水源容易受到污染, 且减少水量[12]。为了确保供水的安 全性, 需要在满足经济以及合理的基础上, 选择应用水源 取水的方法, 把满足不同用水标准的淡水资源以及地下表 水与地下水和海水等, 经过相应的处理确保其在处理后满 足用水要求, 后把处理好的废水以及雨水作为不同行业的 用水资源，真正的做到开源节流[13]。

\section{3. 更新和改善技术, 利用技术进行管控}

一些污染严重的高危企业在生产作业中, 为了取水以 及排水的便利性, 均尝试在接近城市的区域选择水源地, 为了控制意外的发生, 企业在建设和修建水源期间, 需要 把水源建设为独立性、隔离的个体, 这样才能把风险以及 意外控制到最低。此外, 企业也要重视技术的更新和改造, 善于利用科学技术进行管控, 引进新型隔离技术和设备, 重点对雨水以及污水管道进行设置, 做好雨水和污水的预 防与管控工作，以免出现意外问题。

污水处理技术与生产处理技术、设施要共同更新, 同步进行, 确保企业所投产的生产以及污水处理设备相 配套, 尽量控制对水源地的影响。与此同时, 针对工作 人员技术操作要严格管控, 以免因为操作不当导致出现 污染问题。 
城镇供水企业应引进智能化管控技术以及在线监管 技术, 对在线监测设备进行优化配置, 提高测报数据的准 确性。满足当下城镇供水管理以及安全管控实际需求, 相 关部门可以大力尝试和应用[14]。

\section{4. 重视城市管网的优化与改造, 强化高输配水系统安 全性}

(1)从政府的角度来说, 政府相关部门要加强对城 市管道的改造和优化, 倡导和鼓励也要优质的管材材 料, 改造腐蚀以及落后的管网, 避免出现管材的俄日 此污染。

(2)政府需要建立一定周期, 定期防水和冲洗管网内部 的死水区域以及管线终端等相关部位，也要定期对管网实 施清管和刮管以及除垢与涂祄等相关维护与管控、管理工 作。

(3)做好企业管网的管理工作, 重点对供水管网的安全 性进行检查与健康, 坚决抵制城市内部供水管道与其附属 装置和地面以及地下安全范围之内来挖坑和取土, 不可在 城市供水管道附近修建建筑物, 以免对管道带来腐蚀和破 坏，以免管线被污染[15]。

\section{4. 结论}

社会的运行, 城市的发展, 大众的生产和生活, 均 需要水资源作为保障。建设完善城市供水系统, 做好供 水管理以及安全管控工作, 可更好的供应水资源, 为整 个城市以及社会大环境进行供水服务。但是基于目前城 镇供水管理以及供水安全存在较大问题, 包括水资源较 为短缺, 整体水环境严峻、供水管理技术以及监管手段 较为落后、水质量问题以及供水安全问题突出、供水管 网出现老化问题，资金投入不足等问题，导致水源地环 境受到较大污染, 影响供水质量和效果。针对于此, 必 须结合现状以及存在问题, 总结各方面的经验, 制定管 理以及安全管控举措, 优化产业布局, 重视水资源的保 护以及废水、污水的二次回用, 实施开源节流举措, 建 设预警与管理机制, 更新和改善技术，利用技术进行管 控, 重视城市管网的优化与改造, 杜绝官网漏损, 降低 官网故障率, 强化高输配水系统安全性, 使供水管网的 水质达到国家标准。

\section{参考文献}

[1] 张玉叶.城市供水安全综合评价探讨 [J]. 城市建设理论研究 （电子版）,2013,(23):1-4.

[2] 蒋一. 城市供水管网二次污染的原因及其处理对策[J]. 黑 龙江科学,2018,(20):112-113.

[3] 辛宏斌.关于城市典型区域地下水环境质量现状研究 [J]. 干 旱环境监测,2019,(02):55-58.

[4] 王伟. 城镇供水管理及供水安全对策 [J]. 居 业,2021,(01):161-162.

[5] 李元忠. 城镇供水管理及供水安全对策研究 [J].中小企业管 理与科技(上旬刊),2020,(06):28-29.

[6] 王晓丽.自来水水质检测常规处理办法分析 [J]. 环球市 场,2019,(10):374.

[7] 吴惠强.城镇供水管理及供水安全对策讨论 [J].环境与发 展, 2019,30(12):228+230.

[8] 张国街.自来水水质与污染防治措施研究析 [J].中国化工贸 易,2017,(02):159-162.

[9] 高川. 浅析我国国家级工作水质督察实践[J].城市建设理论 研究 (电子版) ,2013,(18):1-4.

[10] 贾钰蓉.关于水环境质量影响因素分析及水生态环境保护 措施探讨[J].农村实用技术,2020,(02):183-184.

[11] 车旭安.城镇供水管理及供水安全对策讨论 [J].住宅与房地 产,2019,(22):202.

[12] 潘瑞松, 赵风斌, 周政.探析水环境质量影响因素及水生态 环境保护措施[J]. 区域治理,2020,(10):138.

[13] 张瑞. 城镇供水管理及供水安全对策讨论 [J]. 四川水 泥,2021,(06):223.

[14] 罗德俊. 城市供水系统几个新技术的应用及发展 [J]. 建筑 电气,2007,(05):22-25.

[15] 吴秀荣.浅析城镇供水管理及供水安全对策[J].中国新技术 新产品,2021,(01):184. 